\title{
Bone Quality Assessment by Quantitative Ultrasound of Proximal Phalanxes of the Hand in Healthy Subjects Aged 3-21 Years
}

\author{
GIAMPIERO I. BARONCELLI, GIOVANNI FEDERICO, SILVANO BERTELLONI, \\ FRANCESCA DE TERLIZZI, RUGGERO CADOSSI, AND GIUSEPPE SAGGESE
}

\begin{abstract}
Endocrine Unit, Division of Pediatrics, Department of Reproductive Medicine and Pediatrics, University
\end{abstract} of Pisa, Pisa, IT-56125, Italy [G.I.B., G.F., S.B., G.S.]; and IGEA Biophysics Laboratory,

Carpi, Modena, IT-41012, Italy [F.T., R.C.]

\section{ABSTRACT}

\begin{abstract}
Bone quality by quantitative ultrasound was assessed in 1083 (587 males) healthy white subjects aged 3-21 y. Amplitudedependent speed of sound (AD-SoS) through the distal end of the first phalanx diaphysis of the last four fingers of the hand was measured by an ultrasound device (DBM Sonic 1200, IGEA, Carpi, Italy). Mean AD-SoS values increased progressively from 3 to 21 y (males, $1845.9-2119.1 \mathrm{~m} / \mathrm{s}, p<0.0001$; females, $1842.3-2098.8 \mathrm{~m} / \mathrm{s}, p<0.0001)$. They did not differ $(p=\mathrm{NS})$ between sexes up to age 11, but females showed higher $(p<0.05$ $-p<0.0001) \mathrm{AD}-\mathrm{SoS}$ values than males in age groups 12,13 , and $14 \mathrm{y}$. There was no difference ( $p=\mathrm{NS}$ ) of AD-SoS values between sexes in pubertal stages 1,2, and 5, but females had higher mean AD-SoS values than males in stages $3(p<0.01)$ and $4(p<0.001)$. Independent predictors of $\mathrm{AD}-\mathrm{SoS}$ were weight, body mass index, pubertal stage, and mean width of fingers in males, and age, pubertal stage, and mean width of fingers in females $(p<0.01-p<0.0001)$. However, $7.8 \%$ in
\end{abstract}

males and 3.6\% in females of the increment of AD-SoS values can be related to the finger anatomy alone. AD-SoS values probably reflect the architectural organization of growing bone or changes in bone elasticity. Increased bone density and size may be additional factors influencing AD-SoS. Measurement of AD$\mathrm{SoS}$ at the hand phalanxes may be a simple, noninvasive, and radiation-free technique to assess bone quality in children.

(Pediatr Res 49: 713-718, 2001)

Abbreviations:
AD-SoS, amplitude-dependent speed of sound
BMI, body mass index
BMD, bone mineral density
CV, coefficient of variation
SCV, standardized coefficient of variation
QUS, quantitative ultrasound
ROI, region of interest

Prospective studies have shown that the incidence of osteoporotic fractures is inversely related to bone mass (1). Peak bone mass is considered a main determinant of BMD in adulthood; thus, maximizing peak bone mass is important for preventing osteoporosis (1). It has been generally accepted that most of peak bone mass at any skeletal site is attained during the mid thirties in both sexes $(2,3)$, but in lumbar spine and in femoral neck, bone mass accumulation is virtually completed in late adolescence to young adulthood (2-4). Thus, failure to gain sufficient bone mass during skeletal growth and the period of bone consolidation may predispose to the development of senile osteoporosis (5). Some years ago Dent (6) and more recently Kreipe (7) suggested that "senile osteoporosis is a pediatric disease." Therefore, the assessment of bone mineral status during childhood and adolescence may be a useful tool

Received May 31, 2000; accepted December 4, 2000

Correspondence and reprint requests: Giampiero I. Baroncelli, M.D., Endocrine Unit, Division of Pediatrics, Department of Reproductive Medicine and Pediatrics, University of Pisa, Via Roma 35, IT-56125 Pisa, Italy; e-mail: g.baroncelli@clp.med.unipi.it in identifying subjects with reduced bone mass who could be exposed to an increased risk of osteoporosis in adulthood.

For preventive studies in large population of children and adolescents, it would be necessary to assess BMD with a technique that is relatively cost-effective and free of ionizing radiation. QUS is a new and noninvasive method of estimating BMD and bone elasticity ( $8-13)$. This technique is safe, easy to use, and radiation-free; the equipment can be transported, and it is relatively cheap in comparison with more expensive densitometric techniques such as dual-energy $\mathrm{x}$-ray absorptiometry and quantitative computed tomography $(13,14)$. Clinical studies showed that QUS was able to discriminate between osteoporotic and healthy women $(11,14,15)$, and it may predict fracture independent of BMD (11). Moreover, QUS seems to be a useful method to recognize osteopenic children $(16,17)$.

In this study we assessed ultrasound velocity at proximal phalanxes of the hand in healthy children and adolescents to obtain normative values for the 3- to 21-y-old population. 


\section{METHODS}

Subjects. We examined 1083 (587 males and 496 females) healthy white subjects, aged 3-21 y, randomly enrolled in nursery, primary, or secondary schools, and in medical school of our university. The subjects were subdivided in 1-y age groups and by sex (Table 1). All subjects were examined by one of us (G.B., S.B.). An extensive clinical history was obtained by interview with the children's parents or the subject as appropriate. All subjects had normal weight and length at birth, and did not take drugs known to affect bone or mineral metabolism. There was no history of any chronic or bone disease. None suffered from bone fractures or diseases at the site of ultrasound velocity assessment. In all subjects, height, weight, and BMI were in the normal age distribution, and their pubertal stage was appropriate for chronologic age.

Consent. Informed written consent to perform the study was obtained from the parents of each subject when the chronologic age of the child was $<18 \mathrm{y}$ and directly from each subject whose chronologic age was $>18 \mathrm{y}$. The study was approved by the ethics committee for human investigation of our department. The headmaster and the school teachers committees of the enrolled schools approved the study.

Assessment of anthropometric findings. Standing height and weight were measured with portable stadiometer and balance, respectively, by one of us (G.B., S.B.). BMI was calculated using the formula weight (in kilograms) divided by height (in square meters). Pubertal stage was assessed according to Tanner and Whitehouse (18).

Ultrasound velocity measurement. The device used (DBM Sonic 1200, IGEA, Carpi, Italy) is based on the transmission of ultrasound through the distal end of the first phalanx diaphysis in proximity of the condyles (ROI) of the last four fingers of the hand. The condyles at the distal diaphysis provide a convenient point for placing the probes, which is an essential feature for reproducibility of measurements $(10,15)$. The distal end of the diaphysis of the proximal phalanxes contains both cortical and trabecular bone, as well as a small medullary canal $(13,19)$; the anatomic ROI is mostly cortical bone (approximately $60 \%)(19,20)$.

Two 12-mm-diameter transducers on a high-precision $( \pm 0.02 \mathrm{~mm})$ caliper, which measures the distance between the two probes, are positioned on the lateral and medial surface of each finger. The emitter probe generates an ultrasound signal with a frequency of $1.25 \mathrm{MHz}$, and the receiver probe receives the ultrasounds that have crossed the phalanx (21). The medial and lateral surface of the phalanx at the ROI is approximately parallel, hence reducing ultrasound scattering (10). The coupling of the probes with the skin is mediated by standard ultrasound gel. The device calculates the speed of sound ( SoS, in meters per second) through the phalanx by measuring the width of the finger (including soft tissues) divided by the time of flight, defined as the time from emitted pulse to received signal, considering the signal that reaches a predetermined minimum amplitude value $(2 \mathrm{mV})$ for the first time; thus, the assessed ultrasound velocity is AD-SoS (21). The probes are gently rotated until the best signal (defined in terms of number of peaks and the amplitude of the peaks) is recorded on the screen. The final result is the average AD-SoS over four fingers. At each measuring session, the reference speed of the subject's soft tissue is measured by applying the probes to the soft tissue area of the first interdigital space. The value is then automatically used by the device when measuring AD-SoS in the phalanx to take account of soft tissue interference.

In all subjects, $\mathrm{AD}-\mathrm{SoS}$ was measured in the nondominant hand by the same operator (G.F.). In addition, the difference between AD-SoS values in dominant and nondominant hands was assessed in 25 (12 males and 13 females) healthy white children and adolescents, aged 7-18 y, by the same operator (G.B.). All the osteosonogrammetry data were stored on a portable personal computer connected to the device.

Precision. Short-time precision was assessed in vivo by measuring AD-SoS in four healthy white children (two males

Table 1. Anthropometric findings of the examined subjects

\begin{tabular}{|c|c|c|c|c|c|c|c|c|}
\hline \multirow[b]{2}{*}{ Age Group, y } & \multicolumn{4}{|c|}{ Males } & \multicolumn{4}{|c|}{ Females } \\
\hline & $n$ & Height $(\mathrm{cm})$ & Weight (kg) & BMI & $n$ & Height $(\mathrm{cm})$ & Weight (kg) & BMI \\
\hline 3 & 11 & $103.9 \pm 3.7$ & $18.0 \pm 2.0$ & $16.7 \pm 1.5$ & 15 & $99.1 \pm 4.6$ & $15.8 \pm 2.0$ & $16.1 \pm 1.6$ \\
\hline 4 & 24 & $108.0 \pm 4.4$ & $18.5 \pm 2.4$ & $15.9 \pm 1.6$ & 21 & $108.0 \pm 3.9$ & $17.8 \pm 2.0$ & $15.2 \pm 1.3$ \\
\hline 5 & 18 & $116.5 \pm 4.8$ & $21.9 \pm 2.4$ & $16.2 \pm 1.7$ & 24 & $114.0 \pm 3.6$ & $20.5 \pm 2.9$ & $15.7 \pm 1.7$ \\
\hline 6 & 23 & $121.3 \pm 4.1$ & $23.3 \pm 3.5$ & $15.8 \pm 1.8$ & 23 & $121.3 \pm 4.9$ & $24.2 \pm 4.8$ & $16.4 \pm 2.2$ \\
\hline 7 & 21 & $128.2 \pm 4.2$ & $27.9 \pm 4.4$ & $16.9 \pm 2.2$ & 26 & $124.8 \pm 3.7$ & $25.0 \pm 3.3$ & $16.0 \pm 1.8$ \\
\hline 8 & 22 & $133.1 \pm 3.5$ & $29.3 \pm 3.4$ & $16.5 \pm 1.6$ & 24 & $130.8 \pm 5.5$ & $29.5 \pm 3.8$ & $17.2 \pm 1.4$ \\
\hline 9 & 18 & $137.4 \pm 4.9$ & $32.1 \pm 4.5$ & $16.9 \pm 1.9$ & 20 & $139.5 \pm 4.7$ & $34.8 \pm 5.6$ & $17.8 \pm 2.1$ \\
\hline 10 & 28 & $142.8 \pm 5.4$ & $35.5 \pm 4.6$ & $17.4 \pm 1.6$ & 19 & $142.1 \pm 4.5$ & $33.4 \pm 3.9$ & $16.5 \pm 1.3$ \\
\hline 11 & 30 & $147.8 \pm 6.0$ & $39.0 \pm 6.6$ & $17.8 \pm 2.3$ & 19 & $152.3 \pm 5.9$ & $43.4 \pm 6.2$ & $18.6 \pm 1.9$ \\
\hline 12 & 25 & $154.3 \pm 6.8$ & $44.6 \pm 9.0$ & $18.6 \pm 2.5$ & 20 & $152.2 \pm 5.3$ & $44.0 \pm 5.2$ & $19.0 \pm 1.9$ \\
\hline 13 & 21 & $162.0 \pm 7.0$ & $50.4 \pm 7.1$ & $19.1 \pm 1.8$ & 20 & $158.1 \pm 5.2$ & $48.3 \pm 5.0$ & $19.3 \pm 1.5$ \\
\hline 14 & 44 & $168.6 \pm 8.4$ & $61.1 \pm 8.2$ & $21.5 \pm 2.1$ & 32 & $161.0 \pm 6.2$ & $53.4 \pm 6.7$ & $20.6 \pm 2.4$ \\
\hline 15 & 65 & $172.7 \pm 7.3$ & $64.4 \pm 8.9$ & $21.5 \pm 1.9$ & 59 & $162.2 \pm 5.5$ & $55.8 \pm 5.4$ & $21.2 \pm 1.9$ \\
\hline 16 & 63 & $174.3 \pm 6.3$ & $66.2 \pm 7.8$ & $21.7 \pm 1.9$ & 48 & $162.6 \pm 6.3$ & $56.8 \pm 7.4$ & $21.4 \pm 1.7$ \\
\hline 17 & 58 & $175.2 \pm 6.2$ & $69.4 \pm 7.9$ & $22.6 \pm 1.9$ & 52 & $162.0 \pm 5.3$ & $56.8 \pm 5.2$ & $21.6 \pm 1.6$ \\
\hline 18 & 55 & $175.8 \pm 5.6$ & $69.9 \pm 7.0$ & $22.6 \pm 1.9$ & 38 & $163.5 \pm 6.4$ & $57.9 \pm 6.8$ & $21.6 \pm 1.8$ \\
\hline 19 & 28 & $177.3 \pm 8.1$ & $71.3 \pm 8.4$ & $22.7 \pm 2.2$ & 11 & $161.8 \pm 4.7$ & $57.6 \pm 5.9$ & $22.0 \pm 1.3$ \\
\hline 20 & 22 & $178.2 \pm 5.7$ & $71.6 \pm 8.2$ & $22.5 \pm 2.0$ & 12 & $162.7 \pm 4.8$ & $55.3 \pm 5.7$ & $20.9 \pm 2.4$ \\
\hline 21 & 11 & $173.8 \pm 6.2$ & $69.6 \pm 5.0$ & $23.1 \pm 1.8$ & 13 & $162.5 \pm 5.5$ & $55.5 \pm 6.8$ & $21.0 \pm 2.1$ \\
\hline
\end{tabular}


and two females, aged 7-8 y) and four adolescents (two males and two females, aged 11-13 y) five times on one day by the same operator (G.B.) with repositioning. After 7-10 d, interoperator precision was assessed measuring $\mathrm{AD}-\mathrm{SoS}$ in the same eight subjects five times on one day by two operators (G.B., G.F.) with repositioning. Precision was expressed by the determination of the $\mathrm{CV}$ for each of the eight subjects using the formula: $\mathrm{CV} \%=(\mathrm{SD} /$ mean $) \times 100$, where mean and $\mathrm{SD}$ are the mean and SD over five repeated measurements. Precision was defined as the mean value of the $\mathrm{CV}$ calculated on the eight subjects. An sCV was derived by normalizing the $\mathrm{CV}$ of each subject to the range over the mean according to the formula $\mathrm{sCV} \%=\mathrm{CV} \% /($ dynamic range/mean) (22). Dynamic range was derived from the difference between the highest $\mathrm{AD}-\mathrm{SoS}$ value measured in the entire population of males or females and the lowest measurable AD-SoS value $(1570 \mathrm{~m} / \mathrm{s})$ recorded in the device. Standardized precision was defined as the mean value of the sCV calculated on the eight subjects.

Statistical analysis. The results are expressed as mean \pm SD. Comparison of the data between males and females was determined using $t$ test for unpaired samples. One-way ANOVA for repeated measurements corrected by the Bonferroni method was used to assess the age influence on $\mathrm{AD}-\mathrm{SoS}$ values with sex. Linear regression analysis by Pearson's formula was performed to determine correlation coefficients between AD-SoS and anthropometric variables or mean width of fingers. Multiple regression analysis was performed to determine the significance of each independent variable (age, height, weight, BMI, pubertal stage, and mean width of fingers) correlated with AD-SoS after adjusting for the effect of the other independent variables. In addition, partial correlation analysis between $\mathrm{AD}-\mathrm{SoS}$ and mean width of fingers controlling for age, height, weight, BMI, and pubertal stage was applied. All statistical analyses were performed using the SPSS for Windows software program (Statistical Package of Social Sciences, version 6.1, Chicago, IL, U.S.A.). A $p<0.05$ was considered significant.

\section{RESULTS}

Variation of AD-SoS during childhood and adolescence. In both sexes, mean $\mathrm{AD}$-SoS values increased progressively from 3 to $21 \mathrm{y}$ (males, $1845.9-2119.1 \mathrm{~m} / \mathrm{s}$, increment $14.8 \%, p<$ 0.0001 ; females, $1842.3-2098.8 \mathrm{~m} / \mathrm{s}$, increment $13.9 \%, p<$ 0.0001). In male subjects, mean AD-SoS values showed a significant increase in the age groups 15 and $16 \mathrm{y}$ in comparison with the 1-y younger age group; in female subjects, mean $\mathrm{AD}-\mathrm{SoS}$ values did not show any change between 1-y age groups (Table 2). There was no difference of mean AD-SoS values between males and females up to age 11 , as well as after 15 , but females showed higher mean AD-SoS values than males in the age groups 12,13, and 14 y (Table 2).

Mean width of fingers increased progressively from 3 to $21 \mathrm{y}$ (males, $11.2-14.6 \mathrm{~mm}$, increment $30.4 \%, p<0.0001$; females, $10.7-13.5 \mathrm{~mm}$, increment $26.2 \%, p<0.0001$ ).

Variation of AD-SoS during pubertal stages. Mean ADSoS values increased significantly from stage 3 to 4 and from stage 4 to 5 in males, and from stage 2 to 3 and from stage 3
Table 2. Mean AD-SoS values per 1-y class through the distal end of the first phalanx diaphysis of the last four fingers of the hand in healthy male and female subjects ages 3-21 y.

\begin{tabular}{ccc}
\hline Age group, $y$ & $\begin{array}{c}\text { AD-SoS, males } \\
(\mathrm{m} / \mathrm{s})\end{array}$ & $\begin{array}{c}\text { AD-SoS, females } \\
(\mathrm{m} / \mathrm{s})\end{array}$ \\
\hline 3 & $1845.9 \pm 25.5$ & $1842.3 \pm 23.0$ \\
4 & $1853.7 \pm 21.5$ & $1862.1 \pm 25.6$ \\
5 & $1880.0 \pm 35.2$ & $1882.6 \pm 21.9$ \\
6 & $1883.5 \pm 35.5$ & $1883.6 \pm 27.3$ \\
7 & $1891.5 \pm 37.4$ & $1887.5 \pm 34.9$ \\
8 & $1924.2 \pm 29.4$ & $1907.0 \pm 38.6$ \\
9 & $1925.9 \pm 38.7$ & $1936.3 \pm 38.2$ \\
10 & $1928.4 \pm 42.3$ & $1944.6 \pm 32.2$ \\
11 & $1949.6 \pm 40.6$ & $1957.5 \pm 50.1$ \\
12 & $1949.5 \pm 45.5$ & $2000.2 \pm 72.0 \dagger$ \\
13 & $1967.8 \pm 42.4$ & $2017.6 \pm 93.4 \S$ \\
14 & $1981.0 \pm 58.0$ & $2034.9 \pm 45.3 \|$ \\
15 & $2032.5 \pm 43.2 *$ & $2046.1 \pm 41.3$ \\
16 & $2067.7 \pm 47.9 \dagger$ & $2059.1 \pm 39.5$ \\
17 & $2091.4 \pm 50.5$ & $2079.2 \pm 50.9$ \\
18 & $2099.2 \pm 43.9$ & $2083.3 \pm 39.5$ \\
19 & $2108.4 \pm 45.9$ & $2088.6 \pm 28.1$ \\
20 & $2115.4 \pm 45.9$ & $2094.5 \pm 34.4$ \\
21 & $2119.1 \pm 38.9$ & $2099.8 \pm 46.1$ \\
\hline
\end{tabular}

Data are expressed as mean $\pm \mathrm{SD}$.

$* p<0.0001$ and $\dagger p<0.002$ in comparison with 1-y younger age group. $\$ p<0.01, \S p<0.05$, and $\| p<0.0001$ in comparison with males having the same chronologic age.

to 4 in females (Fig. 1). Mean AD-SoS values did not differ between males and females in stages 1,2, and 5; but females had higher mean AD-SoS values in stages 3 and 4 in comparison with males (Fig. 1).

Correlation between AD-SoS and anthropometric variables or mean width of fingers. Correlation coefficients between $\mathrm{AD}-\mathrm{SoS}$ and anthropometric variables or mean width of fingers are reported in Table 3. In both sexes, AD-SoS corre-

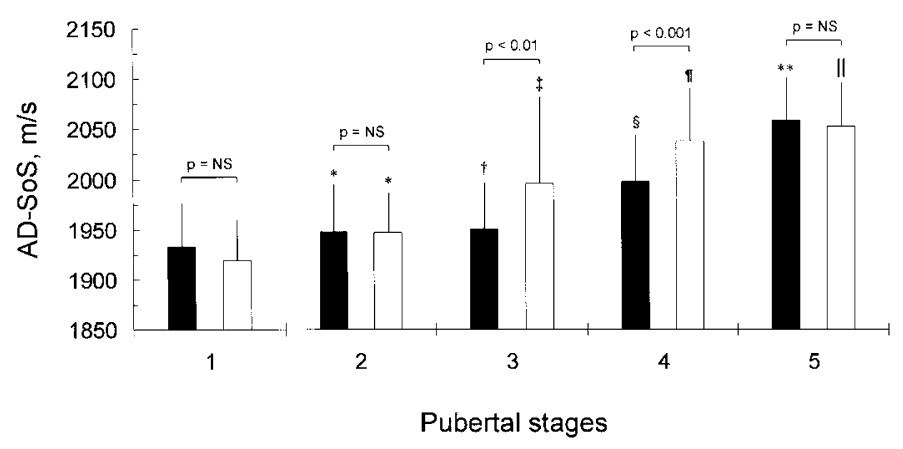

Fig. 1. AD-SoS $(\mathrm{m} / \mathrm{s})$ values through the distal end of the first phalanx diaphysis of the last four fingers of the hand in healthy male (filled columns) and female (open columns) subjects during pubertal stages. Stage 1: males, $n$ $=51$ (age $9-11$ y); females, $n=42$ (age $8-9$ y); stage 2 : males, $n=49$ (age $10-13$ y); females, $n=39$ (age 9-12 y); stage 3: males, $n=39$ (age 12-14 y); females, $n=32$ (age 11-14 y); stage 4: males, $n=39$ (age 14-16 y); females, $n=41$ (age 13-15 y); stage 5: males, $n=116$ (age 15-16 y); females, $n=107$ (age 14-16 y). Data are expressed as mean plus SD. ${ }^{*} p=\mathrm{NS}$ in comparison with stage $1 ; \dagger p=\mathrm{NS}$ in comparison with stage 1 and $2 ; \ddagger p<$ 0.0001 in comparison with stage 1 , and $p<0.001$ in comparison with stage 2; $\S p<0.0001$ in comparison with stages 1,2 , and 3; $\lceil p<0.0001$ in comparison with stages 1 and 2 , and $p<0.002$ in comparison with stage 3 ; $\| p<0.0001$ in comparison with stages 1,2 , and 3 , and $p=\mathrm{NS}$ in comparison with stage $4 ; * * p<0.0001$ in comparison with stages $1,2,3$, and 4 . 
Table 3. Correlation coefficients between $A D-S o S$ and anthropometric variables or mean width of fingers in healthy male and female subjects ages 3-21 y.

\begin{tabular}{lcccccc}
\hline & \multicolumn{2}{c}{ AD-SoS in males } & & \multicolumn{2}{c}{ AD-SoS in females } \\
\cline { 2 - 3 } & \multicolumn{2}{c}{$r$} & $p$ & & $r$ & $p$ \\
\hline Age (y) & 0.87 & $<0.0001$ & & 0.87 & $<0.0001$ \\
Height $(\mathrm{cm})$ & 0.81 & $<0.0001$ & & 0.84 & $<0.0001$ \\
Weight $(\mathrm{kg})$ & 0.77 & $<0.0001$ & & 0.82 & $<0.0001$ \\
BMI & 0.59 & $<0.0001$ & & 0.64 & $<0.0001$ \\
Pubertal stage & 0.74 & $<0.0001$ & & 0.73 & $<0.0001$ \\
Mean width of fingers $(\mathrm{mm})$ & 0.55 & $<0.0001$ & & 0.50 & $<0.0001$ \\
\hline
\end{tabular}

lated significantly with all the anthropometric variables and mean width of fingers. Moreover, age and mean width of fingers were significantly correlated (males, $r=0.74, p<$ 0.0001 ; females, $r=0.65, p<0.0001$ ). In both sexes, multiple regression analysis showed that the composite interaction of all the independent variables was predictive of AD-SoS (males, $r^{2}$ $=0.63, p<0.0001$; females, $\left.r^{2}=0.60, p<0.0001\right)$. As independent predictors of $\mathrm{AD}-\mathrm{SoS}$, weight, $\mathrm{BMI}$, pubertal stage, and mean width of fingers reached significance $(p<$ $0.01, p<0.0001, p<0.0001$, and $p<0.001$, respectively) in males; whereas age, pubertal stage, and mean width of fingers reached significance $(p<0.01, p<0.0001$, and $p<0.01$, respectively) in females. When partial correlation analysis was applied controlling for age, height, weight, BMI, and pubertal stage, AD-SoS remained significantly correlated with mean width of fingers, but there is a little effect on the strength of that correlation (Table 4).

AD-SoS in dominant and nondominant hands. There was no significant difference ( $p=\mathrm{NS}$ ) of AD-SoS values between dominant and nondominant hands in both males (1992.5 \pm $74.9 \mathrm{~m} / \mathrm{s}$ and $1992.3 \pm 73.8 \mathrm{~m} / \mathrm{s}$, respectively; mean difference between the hands, $4.8 \pm 1.7 \mathrm{~m} / \mathrm{s})$ and females $(1993.6 \pm 69.9$ $\mathrm{m} / \mathrm{s}$ and $1994.0 \pm 69.8 \mathrm{~m} / \mathrm{s}$, respectively; mean difference between the hands, $4.5 \pm 1.8 \mathrm{~m} / \mathrm{s}$ ).

Precision. Intra- and interoperator $\mathrm{CV}$ in vivo was 0.55 and $0.91 \%$, respectively. The highest measured AD-SoS value was 2193 and $2198 \mathrm{~m} / \mathrm{s}$, with a dynamic range of 623 and $628 \mathrm{~m} / \mathrm{s}$, in males and females, respectively. Thus, sCV was $1.75 \%$ in males and $1.74 \%$ in females.

\section{DISCUSSION}

In both sexes, mean AD-SoS values at the distal end of the proximal phalanx diaphysis progressively increased during childhood and adolescence. Similar results were found by

Table 4. Partial correlations between AD-SoS and mean width of fingers in healthy male and female subjects ages 3-21 y

\begin{tabular}{|c|c|c|c|c|}
\hline & \multicolumn{2}{|c|}{ AD-SoS in males } & \multicolumn{2}{|c|}{ AD-SoS in females } \\
\hline & $r$ & $p$ & $r$ & $p$ \\
\hline \multicolumn{5}{|l|}{ Mean width of fingers (mm) } \\
\hline Controlling for age $(y)$ & -0.28 & $<0.0001$ & -0.19 & $<0.0001$ \\
\hline Controlling for height $(\mathrm{cm})$ & -0.26 & $<0.0001$ & -0.28 & $<0.0001$ \\
\hline Controlling for weight $(\mathrm{kg})$ & -0.25 & $<0.0001$ & -0.29 & $<0.0001$ \\
\hline Controlling for BMI & -0.19 & $<0.0001$ & 0.09 & $<0.05$ \\
\hline Controlling for pubertal stage & -0.34 & $<0.0001$ & -0.18 & -0.01 \\
\hline
\end{tabular}

Tormo et al. (23) in Spanish children aged 1-8 y, and by Halaba and Pluskiewicz (24) in Polish adolescents aged 9-15 y. Females had higher mean AD-SoS values than males at 12, 13 , and $14 \mathrm{y}$, probably reflecting the earlier onset of pubertal development. During puberty, mean AD-SoS values increased earlier in females (between stages 2 and 3 ) than in males (between stages 3 and 4); females had higher mean AD-SoS values than males in stages 3 and 4 , whereas no sex difference was found in the other stages of puberty.

Ultrasound velocity depends on the material properties of the medium through which the ultrasound wave travels, and there is general agreement that ultrasound velocity is influenced by bone density, architecture, and elasticity $(8-14)$. This suggests that the increment of AD-SoS values we found during childhood and adolescence may reflect an increase of BMD or changes in structural characteristics of bone. Ash weight per unit volume of human skeletons $(25,26)$, as well as radial (27) and femoral (28) bone density assessed by quantitative computed tomography, does not change during life, suggesting that the increase of AD-SoS values with age could be related to the architectural organization of growing bone by changing cortical structure (number of lamellars and secondary osteons) (29-31) and trabecular orientation (changes in the arrangement of the trabecular struts reflecting the anisotropy of bone) (30, 31), number, or thickness. Indeed, studies by radiographic metacarpal morphometry (32-34) showed increased subperiosteal apposition in growing bone leading to increased cortical thickness and cortical area during childhood. A substantial gain in cortical bone on both subperiosteal and endosteal surfaces with a decline of medullary width was observed during adolescence (34). The influence of cortical thickness on AD-SoS is suggested by recent data in vitro $(20,21)$ showing that a reduction of cortical thickness was associated with a reduced AD-SoS. In addition, some studies in human vertebral $(35,36)$ and in bovine radial or femoral $(10,37)$ bone specimens showed that QUS reflected some structural characteristics of trabecular bone mainly related to trabecular orientation. Wuster et al. (13) showed similar results in human phalangeal bone. Furthermore, Hoffler et al. (38) showed that the mechanical properties of bone lamellae, obtained from the lateral portion of femoral neck of human cadavers, were independent of age and sex, suggesting that other factors such as bone mass and structure contributed to the mechanical properties of bone. On the other hand, it has been reported that QUS moderately correlated with BMD $(r=0.40-0.70)$ assessed by densitometric techniques $(11,12,39)$. Therefore, we cannot exclude that the rise of $\mathrm{AD}-\mathrm{SoS}$ values in phalanxes during childhood and adolescence may reflect, at least in part, a small increase in cortical BMD as found at the second metacarpus by roentgen microdensitometry (40), or in trabecular BMD as showed at vertebral bodies in late puberty by quantitative computed tomography, reflecting an increase in trabecular number or thickness $(28,41)$. In this regard, a histomorphometric study on iliac bone specimens in growing children (1.5-22.9 y) demonstrated an age-dependent increase in both cortical width and trabecular bone volume, the latter being caused by an increase in trabecular thickness (42). 
The dependence of AD-SoS on body size and mean width of fingers (bone plus soft tissues) suggests that skeletal mass per se may influence ultrasound velocity. Theoretically, ultrasound velocity should be independent of the dimensions of the sample, as found in vitro by using Perspex blocks having a width in the range of human adult fingers $(11-17 \mathrm{~mm})(20)$. However, this is true only when the sample thickness is very large compared with the wavelength of sound propagation (43). At a sample thickness close to the wavelength of ultrasound, a dispersion occurs and ultrasound velocity decreases with decreasing sample thickness (44). Indeed, as frequency $(f)$ and wavelength $(\lambda)$ are related to each other by the velocity of the sound wave $(c)$ by the equation $c=\lambda f(8)$, if $f$ is the frequency of the emitter probe of our device $(1.25 \mathrm{MHz})$ and $c$ is AD-SoS, in our subjects the value of $\lambda$ would be approximately in the range of $1.5 \mathrm{~mm}$ (age group $3 \mathrm{y}$ ) to $1.7 \mathrm{~mm}$ (age group $21 \mathrm{y}$ ) by the equation $\lambda=c / f$. Therefore, as the frequency of the emitter probe is constant, the dependency of AD-SoS on the mean width of fingers could reflect an increase in wavelength related to changes of bone size or elasticity. According to the correlation between AD-SoS and mean width of fingers, at least $25 \%$ of the observed increase of AD-SoS can be explained by the finger anatomy alone. On the other hand, as age and finger width were closely correlated, at least $42 \%$ of the observed increase of finger width can be explained by the increase of age. However, partial correlation analysis between $\mathrm{AD}-\mathrm{SoS}$ and finger width controlling for age suggested that only $7.8 \%$ in males and $3.6 \%$ in females of the observed increase of $\mathrm{AD}-\mathrm{SoS}$ can be related to the finger anatomy alone. Furthermore, as bone is an anisotropic tissue, there is a directional dependency of ultrasound transmission velocity through bone; in any case, materials with a high elastic modulus, such as bone, can support both longitudinal and shear waves ( $8-10$, 30). Thus, the mode of ultrasound transmission through bone, which depends on its structural characteristics, may also influence AD-SoS.

Thickness or the composition of soft tissue surrounding the finger at the ROI could be an additional factor influencing AD-SoS values. An in vitro study showed that the excision of the soft tissues from cadaver heels produced an increase in ultrasound velocity whereas the subsequent insertion of an artificial layer of fat into the ultrasound path lowered ultrasound velocity (45). It has been also demonstrated in vivo that ankle edema reduced the ultrasound velocity through the heel (46). However, we were unable to investigate the impact of soft tissues on AD-SoS.

We did not find any significant difference between dominant and nondominant hands, as previously reported in adults $(13$, 47), suggesting that it is sufficient to measure AD-SoS of one hand only.

In conclusion, our study shows that AD-SoS measured at the distal end of the proximal phalanx diaphysis of the hand increases during childhood and adolescence, probably reflecting the architectural organization of growing bone or changes of elasticity of bone tissue. In any case, a small increase in bone density or changes of bone size may also influence $\mathrm{AD}-\mathrm{SoS}$ values. Measurement of $\mathrm{AD}-\mathrm{SoS}$ at the hand phalanxes may be a useful tool to assess bone quality in pediatric age in view of the absence of radiation exposure, low cost, and portability of the equipment. However, further studies are needed to establish whether its primary role will be as a complementary measurement or as a replacement for dualenergy x-ray absorptiometry.

Acknowledgment. The authors thank the headmasters, school teachers, and parents who gave their consent to the study and helped us in its organization.

\section{REFERENCES}

1. National Osteoporosis Foudation 1998 Osteoporosis: review of the evidence for prevention, diagnosis, and treatment and cost-effectiveness analysis. Osteoporos Int 8(suppl. 4):S1-S88

2. Bonjour J-PH, Theintz G, Law F, Slosman D, Rizzoli R 1994 Peak bone mass Osteoporos Int 1(suppl.):S7-S13

3. Matkovic V, Jelic T, Wardlaw GM, Ilich JZ, Goel PK, Wright JK, Andon MB, Smith KT, Heaney RP 1994 Timing of peak bone mass in Caucasian females and its implication for the prevention of osteoporosis: inference from a cross-sectional model. J Clin Invest 93:799-808

4. Lu PW, Briody JN, Ogle GD, Morley K, Humphries IRJ, Allen J, Howman-Giles R, Sillence D, Cowell CT 1994 Bone mineral density of total body, spine, and femoral neck in children and young adults: a cross-sectional and longitudinal study. J Bone Miner Res 9:1451-1458

5. Riggs BL, Khosla S, Melton III LJ 1999 The assembly of the adult skeleton during growth and maturation: implications for senile osteoporosis. J Clin Invest 104:671672

6. Dent CE 1973 Keynote address: problems in metabolic bone disease. In: Frame B, Parfitt MA, Duncan H (eds) Clinical Aspects of Metabolic Bone Disease. Excerpta Medica, Amsterdam, pp 1-6

7. Kreipe RE 1992 Bones of today, bones of tomorrow. Am J Dis Child 146:22-25

8. Kaufman JJ, Einhorn TA 1993 Perspective: ultrasound assessment of bone. J Bone Miner Res 8:517-525

9. Genant HK, Engelke K, Fuerst T, Gluer C-C, Grampp S, Harris ST, Jergas M, Lang T, Lu Y, Majumdar S, Mathur A, Takada M 1996 Noninvasive assessment of bone mineral and structure: state of the art. J Bone Miner Res 11:707-730

10. Njeh CF, Boivin CM, Langton CM 1997 The role of ultrasound in the assessment of osteoporosis: a review. Osteoporos Int 7:7-22

11. Gregg EW, Kriska AM, Salamone LM, Roberts MM, Anderson SJ, Ferrell RE, Kuller LH, Cauley JA 1997 The epidemiology of quantitative ultrasound: a review of the relationship with bone mass, osteoporosis and fracture risk. Osteoporos Int 7:89-99

12. Gluer C-C 1997 Quantitative ultrasound techniques for the assessment of osteoporosis: expert agreement on current status. J Bone Miner Res 8:1280-1288

13. Wuster C, Heilmann P, Pereira-Lima J, Schlegel J, Anstatt K, Soballa T 1998 Quantitative ultrasonometry (QUS) for the evaluation of osteoporosis risk: reference data for various measurement sites, limitations and application possibilities. Exp Clin Endocrinol Diabetes 106:277-288

14. Hans D, Njeh CF, Genant HK, Meunier P-J 1998 Quantitative ultrasound in bone status assessment. Rev Rhum Engl Ed 65:489-498

15. Mele R, Masci G, Ventura V, de Aloysio D, Bicocchi M, Cadossi R 1997 Three-year longitudinal study with quantitative ultrasound at the hand phalanx in a female population. Osteoporos Int 7:550-557

16. Jaworski M, Lebiedowski M, Lorenc RS, Trempe J 1995 Ultrasound bone measurement in pediatric subjects. Calcif Tissue Int 56:368-371

17. Baroncelli GI, Federico G, Bertelloni S, Saggese G 2000 Ultrasound data in normal and diseased children. Osteoporos Int 11 (suppl 4): S28-S29 (abst)

18. Tanner JM, Whitehouse RH 1976 Clinical longitudinal standards for height, weight, height velocity, weight velocity and stages of puberty. Arch Dis Child 51:170-179

19. Joly J, Westhovens R, Borghs H, Peeters H, Tirry J, Nijs J, Dequeker J 1999 Reference curve and diagnostic sensitivity for a new ultrasound device for the phalanges, the DBMsonic 1200, in Belgian women. Osteoporos Int 9:284-289

20. Njeh CF, Richards A, Boivin CM, Hans D, Fuerst T, Genant HK 1999 Factors influencing the speed of sound through the proximal phalanges. J Clin Densitometry 2:241-249

21. Cadossi R, Canè V 1996 Pathways of transmission of ultrasound energy through the distal metaphysis of the second phalanx of pigs: an in vitro study. Osteoporos Int 6:196-206

22. Soballa T, Wuster C, Schlegel J, Cadossi R, Isani R, Battista S, Heilmann P, Ziegler R 1998 Ultrasound transmission speed and ultrasound bone profile score of the phalanges in normal women and women with osteoporosis. Horm Metab Res 30:536541

23. Tormo R, Infante D, Taboada A 1995 Ultrasonics and bone mineral density in children. 19th National Congress of Spanish Association for Pediatrics. Alicante, September 21-23 (abstr)

24. Halaba Z, Pluskiewicz W 1997 The assessment of development of bone mass in children by quantitative ultrasound through the proximal phalanxes of the hand. Ultrasound Med Biol 23:1331-1335

25. Trotter M, Hixon BB 1974 Sequential changes in weight, density, and percentage ash weight of human skeletons from an early fetal period through old age. Anat Rec 179:1-18 
26. Laval-Jeantet A-M, Bergot C, Carroll R, Garcia-Schaefer F 1983 Cortical bone senescence and mineral bone density of the humerus. Calcif Tissue Int 35:268-272

27. Schonau E, Wentzlik U, Michalk D, Scheidhauer K, Klein K 1993 Is there an increase of bone density in children? Lancet 342:689-690

28. Gilsanz V, Skaggs DL, Kovanlikaya A, Sayre J, Loro ML, Kaufman F, Korenman SG 1998 Differential effect of race on the axial and appendicular skeletons of children. J Clin Endocrinol Metab 83:1420-1427

29. Sedlin ED 1964 Uses of bone as a model system in the study of aging. In: Frost HM (ed) Bone Biodynamics. Little-Brown and Co, Boston, pp 655-668

30. Kann P 1996 Basics of ultrasound methods for bone analysis. In: Schonau E (ed) Pediatric Osteology: New Developments in Diagnostic and Therapy. Elsevier Science, Amsterdam, pp 161-167

31. Schiedermaier U, Radermacher A, Mokow E, Scheidhauer K, Schonau E 1996 The problems of bone density and ultrasound velocity comparisons. In: Schonau E (ed) Pediatric Osteology: New Developments in Diagnostic and Therapy. Elsevier Science, Amsterdam, pp 175-180

32. Barnett E, Nordin BEC 1960 The radiological diagnosis of osteoporosis: a new approach. Clin Radiol 11:166-174

33. Garn SM, Poznanski AK, Nagy JM 1971 Bone measurement in the differential diagnosis of osteopenia and osteoporosis. Radiology 100:509-518

34. Parfitt AM 1994 The two faces of growth: benefits and risks to bone integrity. Osteoporos Int 4:382-398

35. Nicholson PHF, Haddaway MJ, Davie MWJ 1994 The dependence of ultrasonic properties on orientation in human vertebral bone. Phys Med Biol 39:1013-1024

36. Hans D, Wu CY, Njeh CF, Zhao S, Augat P, Newitt D, Link T, Lu Y, Majumdar S, Genant HK 1999 Ultrasound velocity of trabecular cubes reflects mainly bone density and elasticity. Calcif Tissue Int 64:18-23

37. Gluer C-C, Wu CY, Genant HK 1993 Broadband ultrasound attenuation signals depend on trabecular orientation: an in vitro study. Osteoporos Int 3:185-191
38. Hoffler CE, Moore KE, Kozloff K, Zysset PK, Goldstein SA 2000 Age, gender, and bone lamellae elastic moduli. J Orthop Res 18:432-437

39. Wuster C, Albanese C, De Aloysio D, Duboeuf F, Gambacciani M, Gonnelli S, Gluer CC, Hans D, Joly J, Reginster JY, De Terlizzi F, Cadossi R, and The Phalangeal Osteosonogrammetry Study Group 2000 Phalangeal osteosonogrammetry study: agerelated changes, diagnostic sensitivity, and discrimination power. J Bone Miner Res 15:1603-1614

40. Zamberlan N, Radetti G, Paganini C, Gatti D, Rossini M, Braga V, Adami S 1996 Evaluation of cortical thickness and bone density by roentgen microdensitometry in growing males and females. Eur J Pediatr 155:377-382

41. Seeman E 1998 Growth in bone mass and size: are racial and gender differences in bone mineral density more apparent than real? J Clin Endocrinol Metab 83:14141419

42. Glorieux FH, Travers R, Taylor A, Bowen JR, Rauch F, Norman M, Parfitt AM 2000 Normative data for iliac bone histomorphometry in growing children. Bone 26:103109

43. Kolsky H 1963 Stress Waves in Solid. Clarendon Press, Oxford

44. Ashman RB, Cowin SC, Van Burskirk WC, Rice JC 1984 A continuous wave technique for the measurement of the elastic properties of cortical bone. J Biomech 15:349-361

45. Johansen A, Stone MD 1997 The effect of ankle oedema on bone ultrasound assessment at the heel. Osteoporos Int 7:44-47

46. Kotski PO, Buyck D, Hans D, Thomas E, Bonnel F, Favier F, Meunier PJ, Rossi M 1994 Influence of fat on ultrasound measurements of the os calcis. Calcif Tissue Int 54:91-95

47. Ventura V, Mauloni M, Mura M, Paltrinieri F, de Aloysio D 1996 Ultrasound velocity changes at the proximal phalanxes of the hand in pre-, peri- and postmenopausal women. Osteoporos Int 6:368-375 